Immunology

\section{Seeing the way to B-cell growth}

\author{
from John C. Cambier
}

ANTIBODY produced by the differentiated progeny of B lymphocytes represents a main line of defence against potential pathogens (antigens) such as bacteria and viruses. For decades, immunologists have attempted to define the species which regulate growth and differentiation of $\mathrm{B}$ lymphocytes. These studies, which hold the potential to lead to new strategies for treatment of immune dysfunction, have led to the common perception that Blymphocyte immune responses are regulated by a vast array of $\mathrm{T}$-cell derived molecules - lymphokines - as well as antigen and macrophage products. Noma et al. report on page 640 of this issue ${ }^{1}$ the molecular cloning of complementary DNA encoding a $\mathrm{T}$-cell derived molecule that exhibits multiple B-cellregulatory activities previously ascribed to three different lymphokines. In a paper soon to be published Lee et al. report similar findings ${ }^{2}$. These reports will have considerable impact on our understanding of regulation of $\mathrm{B}$-cell function by $\mathrm{T}$-cell products.

The complexity of lymphokine regulation of B-cell function stands in stark contrast to that of T cells. T-cell growth and differentiation appear to be regulated primarily by antigen recognized in association with molecules of the major histocompatibility complex (MHC) and a single $\mathrm{T}$-cell product, interleukin-2. Evidence

Two distinct candidates for the title interleukin-4 (IL-4) have been launched on the largely unsuspecting public. One is the protein (or glycoprotein) whose DNA sequencing by Honjo's group and a group at DNAX is put into context by John Cambier in the accompanying article. The other candidate is a protein previously termed eosinophil differentiating factor but now shown by C.J. Sanderson et al. of the National Institute of Medical Research, London to be the same as the B-cell growth factor BCGF $_{2}$ (Proc. natn. Acad. Sci. U.S.A. 83, 437; 1986).

Both proteins have a 'right' to be called Il-4 in the sense that an interleukin is merely a substance that carries a message between leukocytes (white blood cells). And in both cases the argument for renaming the protein IL-4 is the need to replace the two or three different names under which the protein has been known, each name reflecting the biological activity through which the protein has been independently discovered and rediscovered. It was an equivalent argument that led to IL-3 being adopted as the from studies of disparate B-lymphocyte responses, which are components of the ultimate immune response, suggests that multiple lymphokines regulate distinct aspects of B-lymphocyte growth and differentiation. Specifically, the definition of B-cell growth factor $1\left(\mathrm{BCGF}_{1}\right)$, was based on its ability to promote proliferation of B lymphoblasts stimulated by anti-immunoglobulin antibody ${ }^{3}$, while another interleukin, $\mathrm{BCGF}_{2}$ (see box), promoted proliferation of $\mathrm{B}$ cells stimulated with dextran sulphate ${ }^{4}$. Lymphokines that promoted proliferating B lymphocytes to differentiate and secrete immunoglobulin $\mathrm{M}$ (ref. 5) and immunoglobulin $\mathrm{G}$ (refs 6,7 ), called $\mathrm{BCDF}_{\mu}$ and $\mathrm{BCDF}_{\gamma}$ respectively, were also described. Finally, a lymphokine was found that stimulates all resting $B$ lymphocytes to increase cell surface expression of class II MHC molecules but did not stimulate them to proliferate ${ }^{8.9}$.

These findings and reports of additional modulatory effects of interleukin-2, interferon- $\gamma$ and interleukin- 1 on lymphocyte function, and others suggesting that supernatants of certain $T$-cell clones ${ }^{10.11}$ contain additional lymphokines that modulate B-cell function, have left the field in a very confused state. The situation is complictated further by the fact that the purity of these factors isolated from complex T-cell supernatants is in many cases

name for a protein involved in the regulation of haematopoiesis and which had been known by several different names reflecting its varied biological activities.

The pity is that IL-4 has now been suggested as the name for two completely different proteins. The clash was known to the authors in advance but an attempt to avoid it failed. One of the issues that came up was whether the title of interleukin should be bestowed on a substance before it has been fully characterized in terms of amino-acid sequence. Certainly there has been a tendency among endocrinologists to call a 'factor' a 'factor' until its full characterization, whereupon it can be given a specific hormonal name. But the short history of the other interleukins does not follow that pattern.

In the end, such matters of nomenclature are the business of committees. The question of which of the two candidates should be called IL-4 will be discussed and may well be decided during the International Congress of Immunology in July. The 'loser' will presumably acquire the name IL-5. suspect and, with the exception of interleukin-2 and interferon- $\gamma$, cloned gene products exhibiting these functional activities did not, until recently, exist.

The situation was simplified somewhat when Ohara et al. ${ }^{12}$ purified to homogeneity a $\mathrm{T}$-cell derived protein of relative molecular mass $\left(M_{r}\right) 20,000$, which they termed BSF-1, that was active in several of the functional assays described previously. This protein exhibited $\mathrm{BCGF}_{1}$ activity ${ }^{12}$, $\mathrm{BCDF}_{\gamma}$ activity $^{13}$ and the ability to induce expression of class II MHC molecules on resting $\mathrm{B}$ cells ${ }^{14}$. This suggested that the same or very closely related lymphokine(s) mediate the multiple activities.

The description in this issue ${ }^{\prime}$ of the cloning of a gene that encodes a protein of $M_{r}$ 20,000 which functions in these three assays is a landmark for several reasons. It demonstrates conclusively that B-cell modulatory activities previously ascribed to multiple species can be mediated by a single lymphokine. Most importantly, it suggests that a single lymphokine interacting with $\mathrm{B}$ cells in distinct differentiative states has different regulatory effects.

This, of course, has far-reaching implications in suggesting that a ligand interacting with its receptor on cells in different states results in activation (or inactivation) of different gene sets. This process could be accomodated by a receptor which switches second-messenger coupling during cell differentiation, or by some as yet undefined genetic mechanism perhaps involving alteration of accessibility of enhancer or promoter sequences during cell differentiation. An alternative explanation is that this lymphokine signals all $\mathrm{B}$ lymphocytes equivalently, making them competent to respond to other currently undefined regulatory species (perhaps autocrine) which direct the qualitatively different responses observed.

The availability of the cloned gene product described by Noma et al. ${ }^{1}$ and Lee $e t$ $a l^{2}$ and isolated B-cell populations in defined differentiative states will allow dissection of this important question.

1. Noma, Y. et al. Nature 319, 640 (1986).

2. Lee, F. et al. Proc, natn. Acad. Sci. U.S.A. (in the press)

3. Howard. M. et al. J. exp. Med. 155.914 (1982)

Swain, S. L etal J exp. Med $158.822(1983)$.

Brooks. K Yuan D Uhr J W Krammer. P.H \& Vitet ta. E.S Nature 302, $825(1984$

6. Vitetta, E.S. et al. Immun. Rev. 78.137 (1984)

7. Sideras, P.. Bergstedt-Lindquist. S. \& Seversin. E. Eur. J. Immun. 15. 593 (1986)

. Roehm, N.W. et al. J. exp. Med. 160. 679 (1984)

9. Noelle, R.. Krammer, P.H. Ohara. J.. Uhr. J.W. \& Vitet ta. E.S. Proc. nat. Acad. Sci. U.S.A. 81. $6149(1984)$

10. Leclerca, L. Bismuth. G. \& Theze. J. Proc. natn. Acad. Sci. U.S.A. 81.6491 (1984)

1. Leclercq, L.. Cambier, J.C. Mishal. Z.. Julius, M.H. \& Theze. J. J. Immun. 136. 539 (1986).

12. Ohara, J., Lahet. I. Inman. J. \& Paul. W.E. J. Immun. 135, 2518 (1985).

3. Vitetta, E.S. et al. J. exp. Med. 162. 1726 (1985)

14. Oliver. K.. Noell. J., Uhr. J.W. Krammer. P.H. \& Vitetta. E.S. Proc, natn. Acad. Sci. U.S.A. 82. $2465(1985)$.

John C. Cambier is Associate Professor at the National Jewish Center for Immunology and Respiratory Medicine, and at the University of Colorado Health Sciences Center, Denver, Colorado 80206 . USA 